\title{
SEMIOTIZANDO DADOS FONÉTICO-ACÚSTICOS: O SENTIDO DA EXPRESSÃO DA FALA NO JORNAL NACIONAL
}

\author{
Conrado Mendes/Universidade de São Paulo
}

\begin{abstract}
RESUMO: Propomos neste artigo a semiotização de dados fonético-acústicos de pesquisa realizada por Mendes (2009), que descreveu como se dá a realização dos arquifonemas /S/ e /R/ no âmbito do principal telejornal brasileiro, o Jornal Nacional. Partindo da premissa hjelmsleviana, de que, assim como o conteúdo, a expressão também carrega consigo um sentido, analisamos a construção desse sentido ao serem realizados tais arquifonemas, ancorados nos pressupostos teórico-metodológicos da semiótica tensiva, especificamente a de Cl. Zilberberg (2006).
\end{abstract}

PALAVRAS-CHAVE: semiótica tensiva; fonética acústica; fonoestilística; Jornal Nacional.

RESUMEN: Proponemos en este artículo la semiotización de datos foneticoacústicos de una investigación emprendida por Mendes (2009), que ha descrito como ocurre la realización de los arquifonemas /S/ y /R/ en el más importante telediario brasileño: el Jornal Nacional. Partiéndose de la premisa hjelmsleviana de que así como el contenido, la expresión también carga consigo un sentido, analizamos su construcción en la realización de tales arquifonemas fondeados en los postulados teórico-metodológicos de la semiótica tensiva, notoriamente la de Cl. Zilberberg (2006). PALABRAS-CLAVE: semiótica tensiva; fonética acústica; fonoestilística; telediario.

\section{INTRODUÇÃO}

Neste artigo, pretendemos semiotizar dados fonético-acústicos de pesquisa por nós desenvolvida (MENDES, 2009), promovendo uma investida semiotizante na esfera da expressão. Visamos especificamente a analisar a construção do sentido da expressão da fala na realização dos arquifonemas /S/ e /R/ no âmbito do principal telejornal brasileiro, o Jornal Nacional. Assim, devido ao isomorfismo dos planos da função semiótica, Hjelmslev mostra ser possível "formar um sentido de expressão” (2006:61). Podemos então afirmar que não apenas do conteúdo podemos depreender sentido, mas também da expressão. Em dita pesquisa, ousamos vislumbrar que sentido seria esse:

Nota-se que, pela análise dos arquifonemas, o foco manteve-se apenas na expressão, o que, entretanto, já carrega consigo um sentido [...]. Um sentido da expressão pautado pela pouca variabilidade poderia sugerir uma lógica dos valores do absoluto sobrepondo-se aos valores do universo, pela perspectiva tensiva (MENDES, 2009, p. 183).

Não obstante, ao fazer uma leitura mais aprofundada da teoria de Claude Zilberberg (2006), que, juntamente de Jacques Fontanille (2001), erigiram o que chamam de ponto de vista tensivo da semiótica, fomos obrigados a rever nossa apreciação. Este artigo, portanto, nasce de uma necessidade de analisar em pormenor a construção do sentido da expressão, ancorando-nos, para tal, nos pressupostos teórico-metodológicos da semiótica tensiva, um dos desenvolvimentos atuais da semiótica de linha francesa. Num primeiro momento, retomaremos brevemente os caminhos e 
alguns resultados encontrados em referida pesquisa para, a seguir, analisar tensivamente a estruturação do sentido da expressão na realização de ditos arquifonemas.

\section{ANÁLISE FONOESTILÍSTICA}

Em Mendes (2009), um dos objetivos da pesquisa foi realizar uma descrição em termos fonéticos da expressão (HJELMSLEV, 2006) da fala (SAUSSURE, 2006) do Jornal Nacional. O estudo fonoestilístico objetivou fazer tal descrição principalmente pelo fato de ter havido um trabalho explicito de padronização de fala de repórteres e apresentadores a partir do ano de 1983. A fonoaudióloga Glória Beuttenmüller, mentora do projeto, buscou amenizar os sotaques regionais dos profissionais da notícia do Jornal Nacional com esse trabalho, que se pautou em um congresso de filologia realizado em Salvador, em 1956, conforme ela mesma relata: "ficou acertado que a pronúncia-padrão do português falado no Brasil seria a do Rio de Janeiro, com algumas restrições. Os 'esses' não poderiam ser muito sibilantes e os 'erres' não poderiam ser muito arranhados, guturais” (ORGANIZAÇÕES GLOBO, 2004, p. 123).

Assim, analisamos o efeito acústico dessa uniformização da fala de repórteres e apresentadores, descrevendo como se dá a realização dos arquifonemas ${ }^{i} / R /$ e /S/ visando a perceber se, de fato, existe tal padronização ou não. Em outras palavras, observamos o grau de variabilidade na produção desses sons.

\subsection{DOS MÉTODOS DAANÁLISE}

Para esse estudo, utilizamos o corpus resultado de uma semana de gravação do $J N$, sendo que, de cada edição, foram selecionadas três matérias, das categorias local, nacional e internacional. O corpus foi analisado no software livre para análise acústica Praat (www.fon.hum.uva.nl/praat/) e conjuntamente foi utilizado o script Beat Extractor traduzido por Barbosa (2006), que segmenta automaticamente segmentos VV, ou seja, de uma vogal até outra vogal.

A opção de analisar os segmentos VV e não apenas vogais e consoantes em separado decorre do fato de o sinal acústico da fala ser um sistema dinâmico e não estático. Sistema dinâmico, na concepção de Barbosa (2006), é aquele que muda de estado com a passagem do tempo e tal mudança é considerada uma propriedade rítmica fundamental. Para a teoria dos sistemas dinâmicos, indivíduo e ambiente se articulam em partes que se relacionam e evoluem no tempo. Esse sistema formado por homem/ambiente obedece a um princípio de auto-organização, de acordo com o qual não há dicotomias entre mente/corpo, planejamento/ execução, programa/executor. Assim, o nível abstrato (mental) é um continuum do nível físico. No sistema dinâmico do ritmo de fala, o autor argumenta que sua unidade mínima é a VV “a duração abstrata de uma unidade delimitada por dois onsets consecutivos como parâmetro de ordem” (BARBOSA, 2006, p. 04). O sistema do ritmo de fala separa o componente prosódico do segmental. O ritmo é o resultado desses dois componentes "mas a organização temporal propriamente rítmica é dada pelo sistema de osciladores acoplados subjacente” (BARBOSA, 2006, p. 27).

A unidade VV foi depreendida a partir do movimento mandibular, a partir da qual se organizam os gestos consonantais em torno da vogal (RHARDISSE \& ABRY apud BARBOSA, 2006). De acordo com o autor, o VV é "cada ciclo do oscilador silábico [que] tem seus limites alinhados com o onset de duas vogais consecutivas” (2006, p. 30). A unidade VV é constituída por uma vogal e todos os segmentos assilábicos que a sucedem, não importando a fronteira silábica, até 
o onset da vogal seguinte, que, por sua vez, determina o início da próxima unidade VV. A periodicidade dessas unidades relaciona-se com o fato de que, na cadeia da fala, observam-se vogais que se interrompem pela perturbação de consoantes. Desse modo, os formantes de uma vogal (ou soante, para a fonética acústica) influenciam os formantes da consoante fricativa seguinte de forma dinâmica. A seguir apresenta-se uma imagem da sentença sem a ajuda de pedreiros, retirada do corpus da pesquisa, segmentada no Praat:

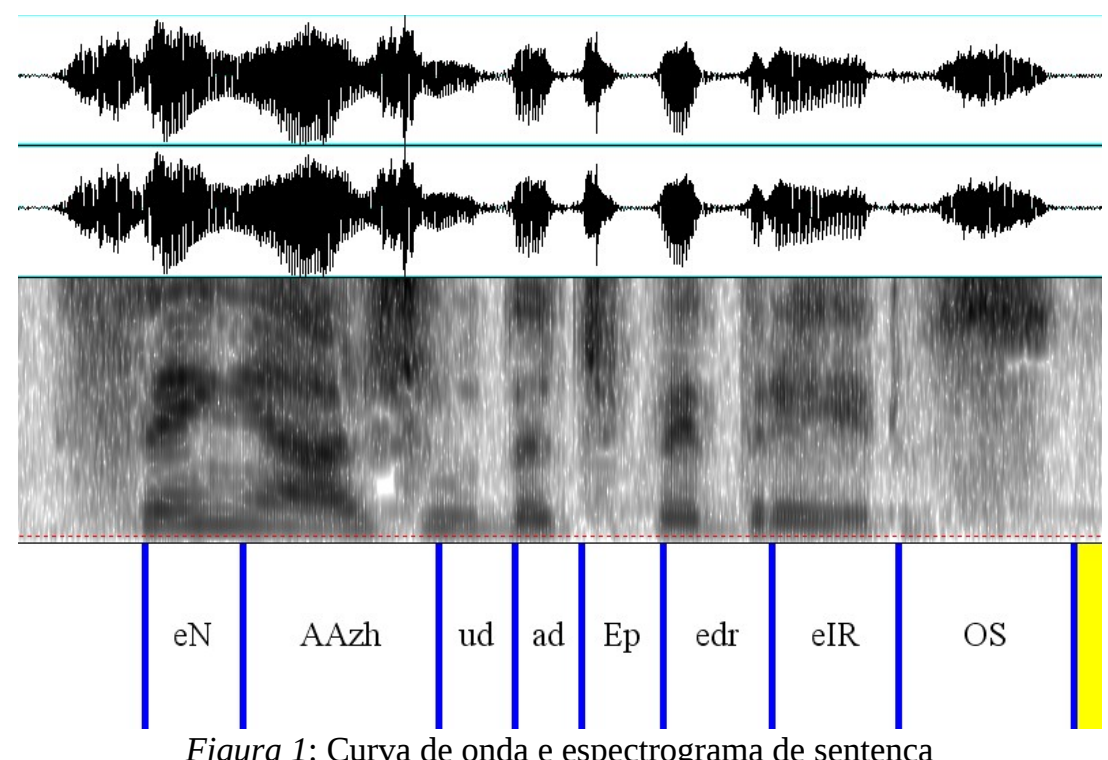

A unidade VV proposta por Barbosa (2006) é vantajosa, pois leva em conta a dinamicidade do sistema da fala. Em outras palavras, caso tivéssemos analisado apenas os arquifonemas /R/ ou /S/ em separado, não teríamos obtido um resultado confiável, pois a configuração formântica de um segmento altera os formantes ${ }^{\text {ii }}$ vizinhos, ou seja, a freqüência das vogais que precedem as consoantes de uma unidade VV vai influenciar-lhes a freqüência. Além disso, Barbosa (2006, p. 56-57) argumenta que a unidade VV é mais estável que a sílaba fonológica, pois existe uma resistência dos onsets vocálicos à perturbação consonantal e prosódica. Dessa maneira, a unidade VV, que possui grandeza de sílaba, cumpre de forma dinâmica a manutenção da regularidade e da periodicidade, funcionando como um atrator cíclico. A regularidade do fluxo vocálico é definida pelo autor como silabicidade, quer dizer, uma produção contínua de unidades que têm o tamanho de uma sílaba.

Após as segmentações, foram feitas transcrições fonológicas, como podem ser vistas na figura acima, gerada pelo programa Praat, com base na tabela proposta por Albano \& Moreira (1996). Optamos pela transcrição fonológica, pois a análise pressupõe que a realização acústica dos sons de cada língua não é fixa, embora exista uma intenção fonológica para cada execução que permite a identificação de sons diferentes mesmo quando sua realização sobrepõe parâmetros acústicos. Assim, a etiquetação é sempre fonológica, descontínua, enquanto os dados para análise são acústicos, numéricos e da ordem do contínuo. Os resultados encontrados no Praat foram, por sua vez, analisados no software livre de análise estatística, chamado $R$ (www.r-project.org). 


\subsection{ANÁLISE DO ARQUIFONEMA/R/}

Os resultados apresentados a seguir têm a ver com a realização do /R/ e, para isso, selecionamos os segmentos /aR/, /AR/, /eR/, /ehR/, /iR/, /ohR/, /oR/, /uR/. Tais segmentos, por serem formados por apenas duas partes, além das razões teóricas apresentadas anteriormente, permitem deduzir a freqüência da realização do $/ \mathrm{R} /$. As tabelas foram formadas a partir de análise de variância ANOVA (multi-way) e foram escolhidas como fatores categoria e segmento e como variável de resposta a média dos quatro primeiros formantes F1, F2, F3, e F4. Apresenta-se agora uma tabela, a do segmento /aR/, para efeito de exemplo e, a seguir, algumas considerações:

Tabela 1

\begin{tabular}{|c|c|c|c|c|c|}
\hline $\begin{array}{c}\text { Segmento } \\
\text { aR }\end{array}$ & F1 & F2 & F3 & F4 & $\begin{array}{c}\text { Número } \\
\text { de } \\
\text { segmento } \\
\text { s }\end{array}$ \\
\hline $\begin{array}{c}\text { Categoria } \\
\text { Internacio } \\
\text { nal }\end{array}$ & 768 & 1540 & 2670 & 3816 & 35 \\
\hline $\begin{array}{c}\text { Categoria } \\
\text { Local }\end{array}$ & 757 & 1557 & 2650 & 3759 & 36 \\
\hline $\begin{array}{c}\text { Categoria } \\
\text { Nacional }\end{array}$ & 780 & 1550 & 2612 & 3832 & 59 \\
\hline $\begin{array}{c}\text { Desvio- } \\
\text { padrão }\end{array}$ & Internacion & Local & Nacional \\
\hline F1 & 113 & 109 & 117 \\
\hline F2 & 147 & 156 & \multicolumn{2}{|c|}{160} \\
\hline F3 & 205 & 163 & \multicolumn{2}{|c|}{165} \\
\hline F4 & 361 & 256 & 239 \\
\hline
\end{tabular}

Observamos em Mendes (2009) que os segmentos /aR/, /AR/, /eR/, /ehR/, /iR/, /ohR/, $/ \mathrm{oR} / \mathrm{e} / \mathrm{uR} /$ apresentam poucas diferenças significativas quanto à freqüência dos quatro primeiros formantes e que a maioria está dentro do desvio-padrão. Além disso, há relativamente poucos desvios-padrão cuja diferença seja estatisticamente considerável. Assim, ao analisar apenas os segmentos em que o /R/, precedido de vogal (que poderia ser realizado de diversas formas pelo fato de ser um arquifonema), e de constatar poucas diferenças significativas quanto à realização desse /R/, pudemos inferir que, a partir dos dados disponíveis, não existe grande variabilidade quanto à realização do arquifonema /R/ no Jornal Nacional.

\subsection{ANÁLISE DO ARQUIFONEMA/S/}

Alisamos também a realização do arquifonema /S/ nos segmentos /aS/, /AS/, /ES/, /OS/. Não foi possível utilizar exatamente os mesmos segmentos das tabelas do /R/, uma vez que muitos deles não apresentaram número significativo, quando se tratou do /S/. De qualquer maneira, mantivemos os segmentos formados por uma vogal $+/ S /$, de modo que a freqüência da realização do /S/ analisado pôde ser deduzida mais facilmente, já que se trata de segmentos compostos de duas partes. Assim como tabela exemplo apresentada acima, tabelas do /S/ foram criadas a partir 
das médias ANOVA (multi-way) no software $R$. Foram escolhidas como fatores categoria e segmento e como variável de resposta a média de F1, F2, F3, e F4.

Destarte, assim como no arquifonema /R/, notamos haver poucas diferenças significativas em relação aos quatro primeiros formantes, ao comparar as categorias nacional versus local; nacional versus internacional e internacional versus local. Confrontamos o F1, o F2, o F3 e o F4 contrapondo-os às categorias, de modo que, o número de formantes (4) vezes o número de categorias (3) multiplicado pelo número de segmentos analisados (4) é igual a 48 possibilidades de haver diferença significativa ou não. Dessas 48 possibilidades, houve sete diferenças significativas (apenas nos segmentos /aS/ e /ES/) e 41 diferenças não-significativas. Em relação ao segmento /aS/, houve diferença significativa em relação aos segundo e terceiro formantes. Quanto ao segmento /ES/, o segundo e o primeiro formantes mostraram diferença significativa. Já os outros segmentos não apresentaram diferença significativa.

Sublinhamos, todavia, que o número de diferenças significativas é pequeno (14,5\%), quando comparado ao número de diferenças não-significativas (85,5\%). Dessa forma, notamos que o grau de variabilidade na realização do arquifonema /S/ também é pequeno. Ao comparar a realização do fonema /s/ à do arquifonema /S/, vimos que, em relação ao /s/ não há diferenças significativas em relação à variação. Assim, o fonema varia menos que o arquifonema, confirmando a literatura segundo a qual o /s/ é mais estável do que o /S/, como aponta Mattoso Câmara (2002). Ressaltamos ainda que a configuração formântica do /S/ muda pouco conforme a categoria do texto, mantendo o contexto fonológico com a vogal precedente. Isso significa que o arquifonema possui um grau de instabilidade maior que do fonema numa locução que visa a um alto controle e estabilidade fonológica, como é a locução do $J N$. No entanto, salientamos que, embora o arquifonema apresente alguma variação pelos dados exibidos, essa variação é mínima, já que há escassas diferenças significativas nas tabelas que analisaram o arquifonema /S/.

\subsection{Considerações sobre padronização da fala no $J N$}

Dessa forma, mostramos a existência de pouquíssima diferença significativa entre a média dos formantes dos arquifonemas /R/ e /S/ ao contrapor matérias das categorias nacional, local e internacional. Isso significa que o grau de variabilidade em relação à realização de tais arquifonemas é muito baixo. Assim, é possível afirmar que um repórter do eixo Rio-SP-Brasília realiza os arquifonemas em questão de forma semelhante ao repórter que se encontra na região Sul ou Norte, por exemplo. Os dados fonéticos, analisados estatisticamente, apontam, portanto, para uma uniformização, ou uma pequena variabilidade em relação à realização dos arquifonemas /R/ e /S/. Nossa investigação se pautou pelas próprias diretrizes do Jornal Nacional, que sugeriu que o /R/ não devesse ser "muito arranhado, gutural” e o /S/ (...) muito "sibilante” (ORGANIZAÇÕES GLOBO, 2004, p. 123). Portanto, se houve uma intenção em padronizar a fala de repórteres e apresentadores do noticiário mais assistido da TV brasileira, nossa pesquisa (MENDES, 2009) pôde confirmar tal uniformização.

\section{SEMIOTIZANDO DADOS FONÉTICO-ACÚSTICOS}

Antes da análise semiótica propriamente dita, retomaremos alguns pontos da teoria que julgamos cruciais ao entendimento de sua aplicação. Zilberberg (2006) afirma ser a peculiaridade do ponto de vista tensivo discernir as condições de uma reciprocidade entre o afeto e a forma, o sensível e o inteligível. Coloca-se então uma questão embaraçosa que é em que posição colocar esse 
sensível. O autor parece oferecer respostas convincentes ao elaborar o projeto que chama de gramática do afeto, sem que tal expressão constitua um oximoro, segundo ele mesmo ressalta. A trazida do afeto, da foria e da estesia para o centro de interesse da semiótica não se deu num primeiro momento da história da disciplina, pois esse deslocamento implicou admitir que o sensível é uma categoria de primeira ordem que rege, que governa o inteligível. Aos estados de alma, que ganharam destaque principalmente a partir de Semiótica das paixões (1993), coube a função primeira de comandar os estados de coisa. O lugar que o afeto passa então a ocupar, ou seja, o cerne da semiótica, não ocasiona poucas conseqüências: o adjunto adverbial de modo ganha status de intensidade e um segundo acarretamento é a importância concedida ao acontecimento, de modo a se fazer repensar toda a estrutura do discurso: ao lado da estrutura implicativa, outra ganha importância inédita: a concessiva. À concessão, que sempre ocupou poucos parágrafos nos compêndios gramaticais, cabe agora um papel de enorme destaque na semiótica do acontecimento.

Esses são alguns dos desdobramentos - cujos alcances e decorrências não são pequenos - da virada fenomenológica por que passou a semiótica discursiva. Da seara filosófica, a semiótica valeu-se do conceito de campo de presença, o espaço da tensividade, isto é, onde se entrecruzam intensidade e extensidade. A primeira, como dissemos, reporta aos estados de alma, ao sensível, ao passo que, a segunda tem a ver com os estados de coisa, o inteligível. Num primeiro momento, Zilberberg (2006) chama tais grandezas de valências e a correlação valencial ganha o nome de valor.

Sendo que a análise, num sentido hjelmsleviano, trata-se de uma divisão, cabe notar quais são os funtivos de cada valência ou de cada dimensão, como o autor passa a chamar tais grandezas. A intensidade forma-se pelos pares impactante vs. fraco/tênue, e a extensidade, por sua vez, pelos pares concentrado vs. difuso. São esses pares que controlam o acesso ao campo de presença. Assim, sob a perspectiva da intensidade, uma grandeza introduz-se nesse campo pautada por um impacto, por uma força de irrupção. Do ponto de vista da extensidade, é a partir de triagens e misturas que ela se constitui. O gráfico a seguir exemplifica a constituição do campo de presença, circunscrito pelas dimensões da intensidade e da extensidade.

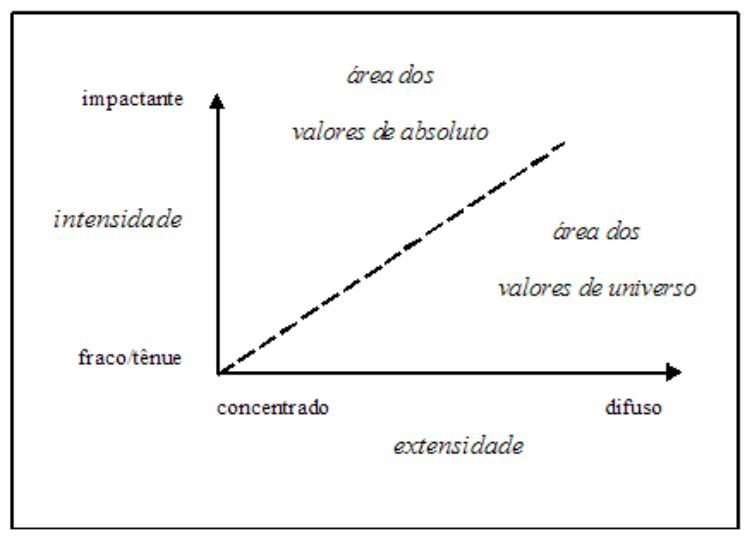

Gráfico 1

Em Zilberberg (2006), as dimensões intensidade e extensidade subdividem-se em andamento/tonicidade e temporalidade/espacialidade. Como a intensidade rege a extensidade, o andamento governa a temporalidade, ao passo que a tonicidade dirige a espacialidade. Quando a intensidade cresce de modo diretamente proporcional à extensidade, trata-se da relação conversa; quando, ao contrário, uma aumenta e a outra diminui, configura-se uma relação inversa, como mostram os gráficos seguintes: 


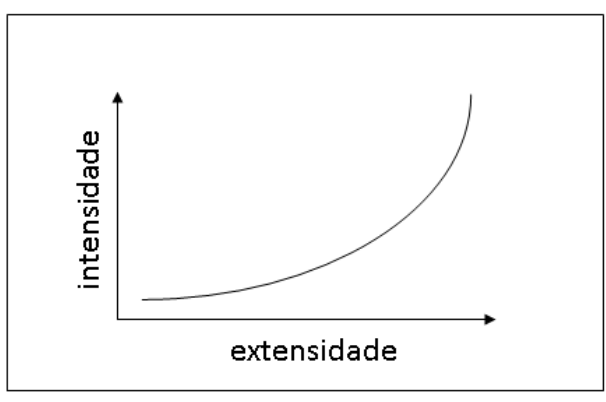

Relação conversa

Gráfico 2

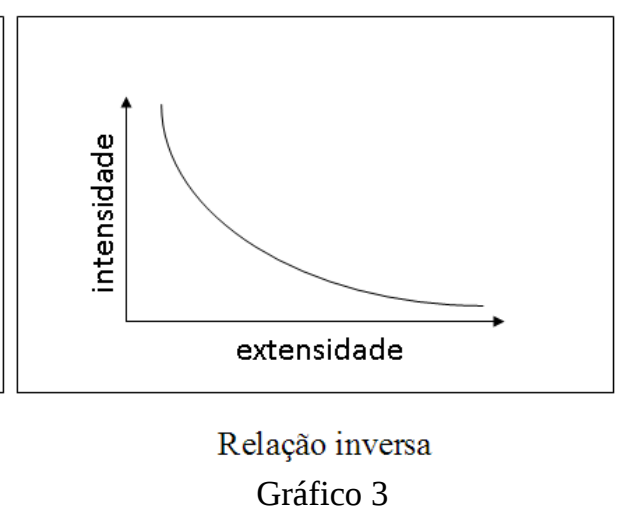

Quanto às subdimensões, o autor diz ser o impacto o produto do andamento e da tonicidade, ou seja, aquilo que ele chama de "significado inapreciável de toda a exclamação" iii ou, em outras palavras, um sensível levado ao seu mais alto grau e, em contrapartida, um inteligível que se reduz a sua escala mínima. O produto das extensões temporal e espacial é, por seu turno, a universalidade. Para efeito de fechamento dessa rápida explanação, Zilberberg (2006) chama então de valência não mais a intensidade e a extensidade ${ }^{\text {iv }}$, que passam a se chamar subdimensão. A valência passa a ser o cruzamento de uma subdimensão (andamento/tonicidade e temporalidade/espacialidade) com um forema, que é, por assim dizer, o lugar a partir do qual se aspectualizam tais subdimensões. Esses são, portanto, os conceitos sobre os quais estruturaremos nossa análise do sentido da expressão.

Como expusemos em Mendes (2009), existe pouca variabilidade na produção dos arquifonemas /S/ e /R/ no Jornal Nacional e que tal uniformização remonta a um trabalho fonoaudiológico que objetivou promover a triagem de alguns fonemas em detrimento de outros. Para Zilberberg (2006), a problemática social (e acrescentaríamos que também a socioletal) é de ordem extensiva: "a partir do momento em que o sujeito procede mediante triagens e misturas interligadas, ele se vê obrigado, quer queira, quer não, ora a incluir excluídos, ora excluir incluídos”. Assim, problemática de natureza extensiva a que se refere o autor, que opera por meio de triagens e misturas, configura também essa problemática socioletal, que exclui alguns fonemas, ao incluir outros. Sabemos que a construção dessa fala que busca uma pretensa neutralidade liga-se, certamente, a razões mais ideológicas que a razões lingüísticas, tal como demonstramos em investigação que versou sobre a natureza ideológica da expressão da fala do $J N$ (MENDES, 2006). Isso justifica o fato de esse noticiário ser um centro irradiador de uma arquinorma: "[o Jornal Nacional], progressivamente, devido ao seu poder de acesso ao público nacional e internacional tem sido agente de estandardização da pronúncia brasileira” (SILVEIRA, 2008, p. 17).

Desse modo, ao promover a triagem de alguns poucos fonemas relativos aos alofones /S/ e /R/, o Jornal Nacional, à primeira vista, age unicamente pela lógica da exclusão, que, por sua vez, sobrepõe-se à lógica da mistura, dos valores do absoluto. Como vimos, a extensidade articula o par concentrado e difuso. Ao operar por meio da triagem, no eixo da extensidade, a pouca variabilidade na realização dos arquifonemas em questão faz com que essas grandezas se constituam próximas à região do concentrado do campo de presença. Entretanto, como apontamos na introdução deste artigo, uma leitura mais aprofundada na teoria zilberberguiana nos fez rever tal posição, que, embora não estando incorreta, ainda prescinde da análise da intensidade. Isso porque uma extensidade está sempre ligada, ou ainda, é sempre regida por uma intensidade.

Desse modo, se tal pequena variabilidade, no eixo da extensidade, opera por triagem, no eixo da intensidade, podemos dizer que ela opera por baixo impacto. Lembramos que o contrário 
do impactante é o fraco/tênue, pares articulados pela intensidade. Desse modo, ao buscar uma expressão da fala pouco impactante, o $J N$ concede a essa expressão um lugar de pouquíssimo destaque, tal como deve ser um texto utilitário. Mirian Chrystus, em sua tese de doutoramento, figurativiza à justa medida a primazia do conteúdo sobre a expressão no Jornal Nacional:

Espécie de utopia midiática, o telejornal persegue uma espécie de linguagem 'branca' isto é, sem marcas autorais, semelhante ao sonho borgeano de um conto passível de ser lido em qualquer língua, em qualquer tempo (2007, p. 143).

O contrário aconteceria se a variabilidade fosse grande, ou em outras palavras, caso operasse, no eixo da extensidade, pela lógica da mistura. Nesse caso, o eixo da intensidade, por sua vez, responderia operando por um impacto forte. Por exemplo: se o Jornal Nacional fizesse uso de um grande número de "sotaques", essa prática causaria grande impacto, disfórico, uma vez que a linguagem telejornalística busca o efeito de maior neutralidade possível, tanto em termos de conteúdo, como em termos de expressão ${ }^{\text {vi }}$.

Assim sendo, podemos dizer que o sentido da expressão da fala do $J N$, em específico sobre a realização dos arquifonemas /S/ e /R/, caracteriza-se pela correlação, no eixo da intensidade, do fraco/tênue e, no eixo da extensidade, do concentrado. Chegamos assim a uma relação [/menor impacto/ - /maior concentração/] ou, em outras palavras, quanto maior a concentração, a triagem, menor o impacto da expressão da fala. Essa correlação tensiva tende tanto à concentração, quanto ao baixo impacto, à tenuidade. Assim, podemos dizer que tal correlação se caracteriza como conversa, pois quanto maior a concentração, maior a tenuidade (ou menor o impacto) e vice-versa, como se vê no gráfico:

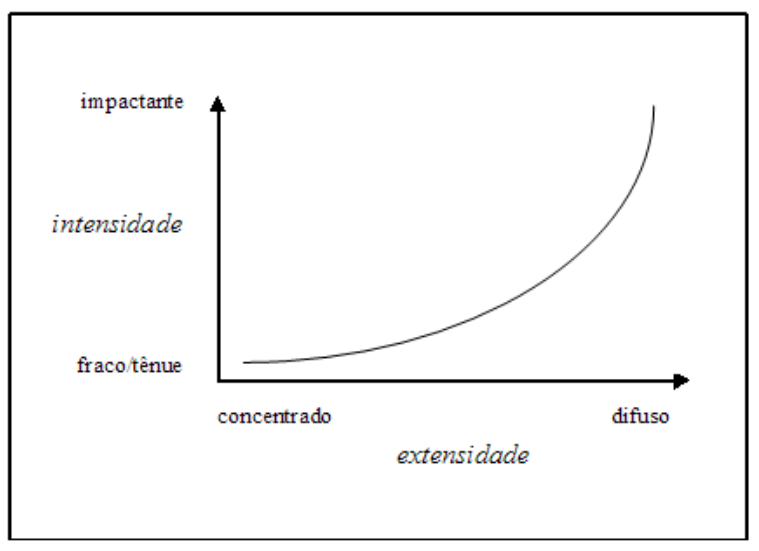

Gráfico 4

Por fim, não podemos então afirmar que o sentido da expressão fala do $J N$, ao analisarmos os arquifonemas /S/ e /R/, tenda somente aos valores do absoluto: ela se encontra precisamente no limiar dessas duas regiões, pouco intensa e pouco extensa, como vemos a seguir: 


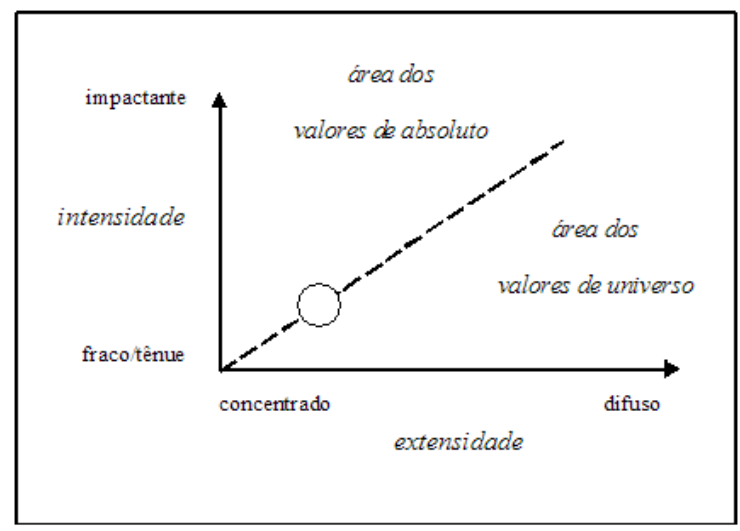

Gráfico 5

\section{CONSIDERAÇÕES FINAIS}

Ao empreendermos uma investida semiotizante no campo da fonética acústica ou, mais especificamente, da fonoestilística, objetivamos demonstrar, sustentados pela premissa hjelmsleviana evidenciada na introdução deste texto, que o sentido da expressão pode se formar independente do sentido do conteúdo, graças ao isomorfismo dos planos da função semiótica e também à possibilidade de se trabalhar analiticamente em separado expressão e conteúdo. A semiótica tensiva mostrou-se uma ferramenta valiosa, pois nos permitiu analisar a construção do sentido da expressão da fala do Jornal Nacional por meio da correlação sensível/inteligível - a partir das noções de triagem, mas também pela de baixo impacto. Desse modo, a expressão da fala tem por si só um sentido, pois penetra no campo de presença correlacionando estados de alma e estados de coisa, intensidade e extensidade.

\section{REFERÊNCIAS BIBLIOGRÁFICAS}

ALBANO, Eleonora Cavalcante, MOREIRA, Agnaldo Antônio. Archisegment-based letter-tophone conversion for concatenative speech synthesis in Portuguese. In ICSLP-1996, 1708-1711, 1996.

BARBOSA, Plínio A. Incursões em torno ao ritmo de fala. Campinas: Pontes Editores, São Paulo: FAPESP, 2003.

CÂMARA JUNIOR, Joaquim Mattoso. Estrutura da língua portuguesa. 35ª ed. Petrópolis: Editora Vozes, 2002.

CHRYSTUS, Mirian. Claro Enigma: A diç̧ão nacionalista em pactos literários e jornalísticos. Tese de doutorado. UFMG, 2007.

CRYSTAL, David. Dicionário de lingüística e fonética. Rio de Janeiro: Jorge Zahar Ed., 2000.

FONTANILLE, Jacques, ZILBERBERG, Claude. Tensão e significação. Tradução de Ivã Carlos Lopes; Luiz Tatit; Waldir Beividas. - São Paulo: Humanitas/Discurso Editorial, 2001.

GREIMAS, Algirdas Julien, FONTANILLE, Jacques. Semiótica das paixões: dos estados de coisa ais estados de alma. Editora Ática: São Paulo, 1993.

HJELMSLEV, Louis. Prolegômenos a uma teoria da linguagem/ Louis Hjelmslev: [tradução J. Teixeira Coelho Netto]. São Paulo: Perspectiva, 2006. 
MENDES, Conrado Moreira. A expressão e o conteúdo da fala do Jornal Nacional. Dissertação de Mestrado. Universidade Federal de Minas Gerais, 2009. (Disponível em: $<$ http://www.letras.ufmg.br/poslin/defesas/1250M.pdf $>$.

MENDES, Conrado Moreira. O falar do Jornal Nacional: produção e recepção de um sotaque de natureza ideológica. Monografia de conclusão do curso de Comunicação Social. Universidade Federal de Minas Gerais, 2006. Disponível em: < http://www.bocc.ubi.pt/pag/mendes-conrado-0falar-do-jornal-nacional.pdf $>$.

ORGANIZAÇÕES GLOBO. Jornal Nacional: a notícia faz história/Memória Globo. Rio de Janeiro: Jorge Zahar Ed., 2004.

SAUSSURE, Ferdinad. de. Curso de lingüística geral / Ferdinand de Saussure; organizado por Charles Bally, Albert Sechehaye; com colaboração de Albert Riedlinger; prefácio da edição brasileira Isaac Nicolau Salum; tradução de Antônio Chelini, José Paulo Paes Izidoro Blikstein. -27. Ed. -- São Paulo: Cultrix, 2006.

SILVEIRA, Regina. C. P. da. Uma pronúncia do português brasileiro. São Paulo: Cortez, 2008. ZILBERBERG, Claude. Elements de grammaire tensive. Limoges: PuLIM, 2006. 
i Para Crystal (2000), o alofone é uma variação perceptível de uma unidade lingüística, sem afetar a identidade funcional. A variação formal não é linguisticamente distintiva, quer dizer, não há mudança de sentido.

iiFormantes correspondem aos picos de energia da onda sonora. No espectrograma são representados pelas regiões mais escuras.

iii Versão provisória dos tradutores L. Tatit, I. C. Lopes e W. Beividas de Elements de grammaire tensive.

iv Em Tensão e significação o termo valência corresponde ao par intensidade e extensidade.

v Idem nota de número 3.

vi Essa preocupação se verifica tanto na expressão da fala, como em outras expressões que sincreticamente se articulam à expressão sonora. Quanto à imagem, por exemplo, podemos destacar a existência de um cenário azulado, roupas em tons neutros e cortes de cabelo discretos, que não desviam a atenção do conteúdo do texto principal: a notícia. 